\title{
Decades of Sustainability
}

\author{
Charles A. Wood ${ }^{1}$, Jackie Shia², Lori Kudlak², and Laura Ondeck² \\ ${ }^{1}$ Center for Educational Technologies, Wheeling University, Wheeling, West Virginia and ${ }^{2}$ Challenger Learning Center, Wheeling University, Wheeling, West Virginia
} Keywords: STEM Education, Simulations, Sustainability, Service for a Fee

Publication Date: October 21, 2020

DOI: https://doi.org/10.15695/jstem/v3i3.07

\begin{abstract}
Since 1998, educators at Wheeling Jesuit University's Challenger Learning Center and Center for Educational Technologies have created realistic live simulations of science and medical emergencies in which students act as astronauts, scientists or doctors to solve STEM problems such as diagnosing diseases, stopping epidemics, picking a safe spacecraft landing spot, and rescuing stranded astronauts. These 90 to 120 -minute simulations, e-Missions, are videoconferenced into classrooms, with companion websites providing pre-mission preparation, supplemental resources and teacher tutorials. e-Missions have been used more than 11,000 times at schools in 50 states and 22 nations. More than 310,000 elementary, middle and high school students have role-played STEM experts, and 10,000 teachers were trained to use technology and problem-based learning. Shorter live missions, e-Labs, were created to demonstrate science topics in 3-9 grade classrooms, and $e-L a b s \mathrm{Jr}$ do the same for K-3. The simulations and $e-L a b s$ are developed with funding from agencies, foundations and corporations, and are maintained through payments by schools of $\$ 400$ to $\$ 550$ for each e-Mission, and $\$ 200$ for $e-L a b s$, often year after year as culminating events for relevant curricula. More than \$5 million dollars have been earned over the last 20 years, supporting the sustained delivery of these innovative STEM experiences, and software and hardware updates. Evaluations have identified positive changes in e-Mission student attitudes and perceptions toward science and science careers.
\end{abstract}

\section{INTRODUCTION}

Sustainability - The Problem. Many excellent STEM education activities result from external funding that typically supports the cost of creation and evaluation of the new activity. Commonly, the activity's actual use is not supported by continuing funding and there are few opportunities to financially support its future use. For example, even a legacy website, such as Exploring the Environment (http://www. ete.cet.edu) which still receives about a million/hits per year about a decade after funding ended, requires modification following updates of operating systems and random glitches. The site is freely available and generates no income for maintenance. Although we have seen no relevant data, it is likely that many other STEM activities, even excellent ones, have limited and perhaps little long-term use because of failure to include sustainability in project design. Since agencies are unlikely to continuously fund dissemination and activity use, schools and sponsors ultimately must (and we find, will) pay for activities as long as they advance learning goals of the schools.
The Challenger Learning Center Onsite Model. Our solution to maintaining sustainability was modeled after educational simulations developed by the national Challenger Learning Center (CLC) program in the late 1990s; they charge schools for unique learning experiences in physical space simulators (https://www.challenger.org/). The CLC concept was advocated by the families of the Challenger Space Shuttle astronauts who died in the tragic launch accident in January 1986. These families did not want the trauma of the widely-watched Challenger explosion to frighten children and turn them away from exploration, in space or elsewhere. With government and corporate funding, physical simulators of a mission control room and an on-orbit spacecraft science lab were designed and centrally produced, along with curricula for space flight simulations requiring use of math and science to solve mission critical problems (Figure 1) Over time, about 50 museums and other education enterprises (including Wheeling Jesuit University) purchased the mission hardware, software, scripts and 


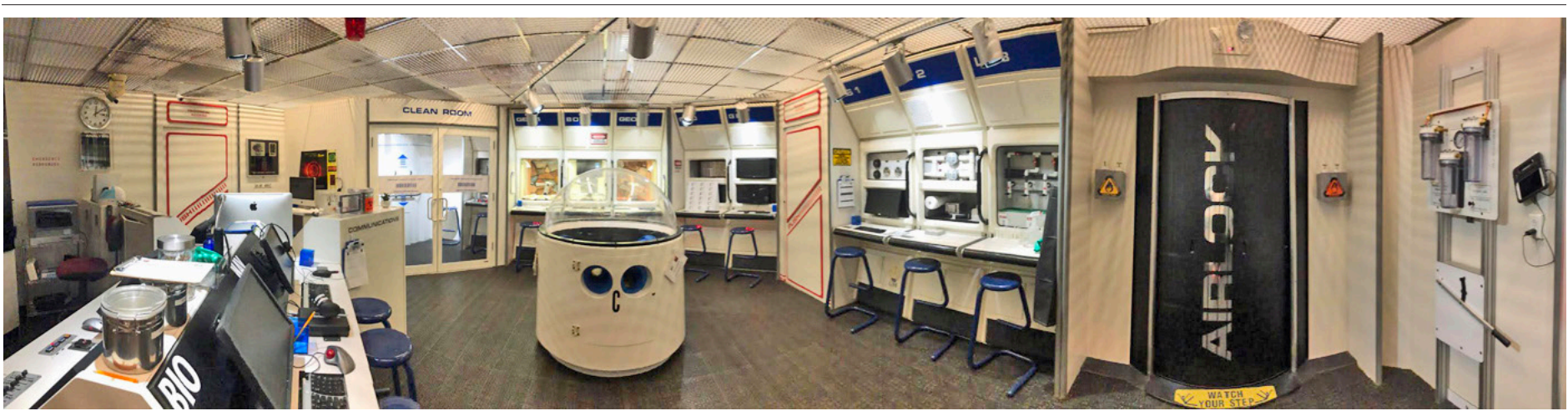

Figure 1. A panoramic view of a traditional Challenger facility that models an orbiting spacecraft laboratory. A companion space mimics Houston's mission control. During each CLC onsite mission, students gain experiences from both mission control and the space lab.

training to establish local CLCs.

Classrooms of students travel by bus to a CLC site, making it an out-of-the classroom special event, to participate in simulations led by CLC educators, dressed in NASA-like blue jumpsuits, who play the role of mission flight directors. Typically, three flight directors work each mission, which lasts two hours. Constructing the physical simulator and continually paying for significant staffing causes the traditional CLC onsite experience to be expensive to build and maintain, but the concept is outstanding. Evidence is that educators and students value the virtual in-space experience, as indicated by continuing payment year after year, for onsite visits. As an example from our Wheeling CLC (WCLC), over the last 20 years school administrators have paid for all 7th grade students in Ohio County, WV to fly a mission at the WCLC, and many local adults continue to talk about the inspiring experience they or their children had. The WCLC on-site missions have memorable impact - in fact, two of our prior middle school students now have engineering jobs with NASA.

\section{METHODS}

Our Sustainability Solution - e-Missions. Challenger onsite missions are sustainable but at costs that can be met only

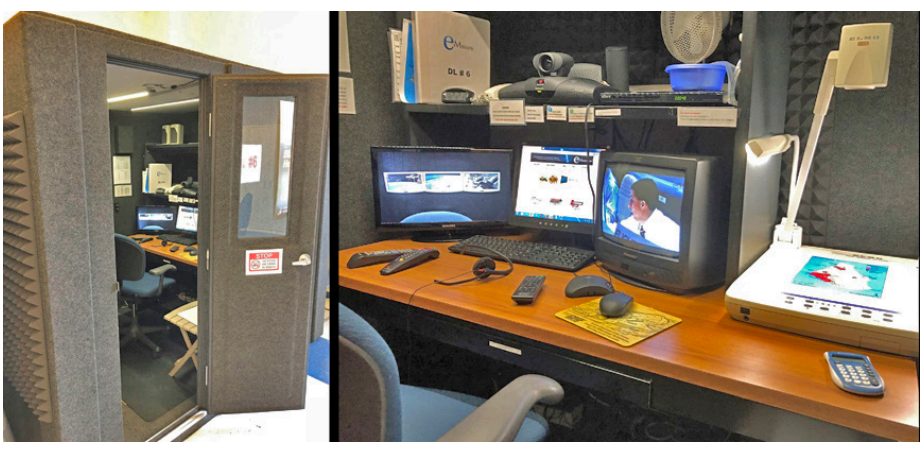

Figure 2. An e-Mission is led by a flight director sitting within a soundproof booth (left) containing digital equipment for video-conferencing, and displaying to students, videos and images of mission location, maps and data (right). if enough school visits can occur. Due to the mountainous nature of $\mathrm{WV}$, it is time-consuming and costly for a classroom of students to travel by bus to Wheeling for an onsite Challenger mission. Our solution is to take the mission to the students, wherever their schools are.

Twenty-two years ago, the Wheeling Jesuit University CLC team created an online version of a CLC simulation - an e-Mission - that would recreate the uniqueness of an onsite spacecraft mission but on computer screens in classrooms, while maintaining live video communication with an educator dressed in a blue jumpsuit. For two decades, schools have paid for their students to role-play scientists, doctors, astronauts and explorers, while maintaining real-time interactions, via video-conferencing, with Challenger educators who guide them as Chief Medical Officers, Mission Commanders and other relevant professional leader roles. Students learn about science, the scientific method, careers and collaboration to solve important and complex scientific problems, all the while being immersed in a captivating experience.

Since 1999, 60\% of the WCLC missions have been e-Missions, video-conferenced from soundproof booths with backdrops and flight director educator clothing appropriate to each mission's theme (Figure 2). For example, flight directors for the medical missions associated with NIH projects wear white lab coats, and stethoscopes hang from their necks. For NASA-funded missions, the flight directors wear the blue jumpsuits, and background pictures show spacecraft, astronauts and planets.

Our first online simulation, Operation Montserrat (OM; http://www.e-missions.net/om/), was developed in 1998, and is still presented via video conferencing in hundreds of classrooms every year (Figure 3 ). The key elements of $O M$ and subsequent simulations are a scenario incorporating a realistic and important problem to be managed; specific roles for four or five 6-person student teams; and a Challenger educator acting as a commanding official who gently and minimally guides students to analyze data and take actions to resolve the problem. In $O M$, the scenario is 


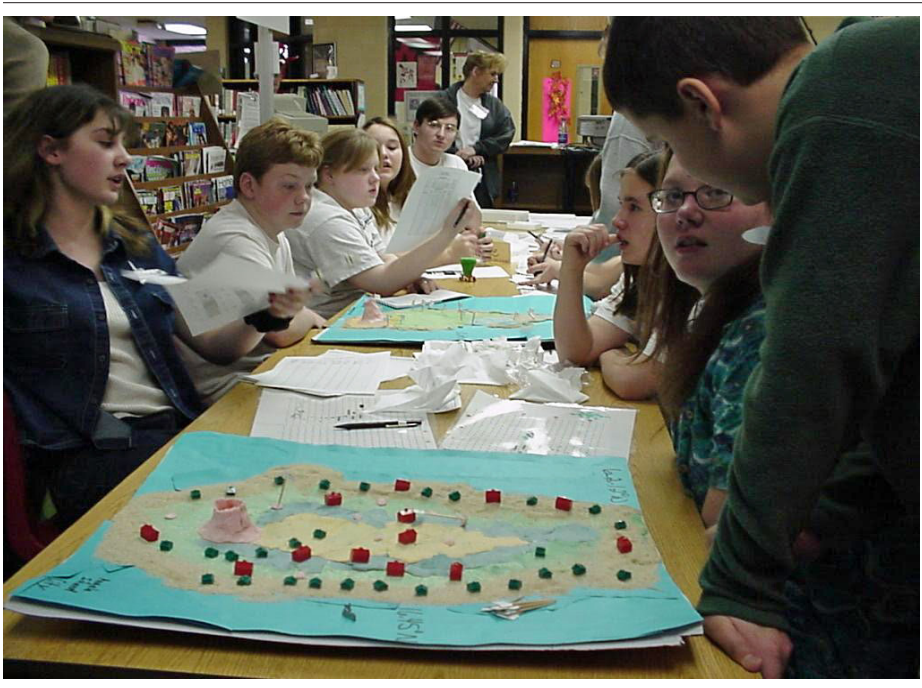

Figure 3. During the Operation Montserrat e-Mission, middle school students use maps and other data to determine where to evacuate the island's population based on calculations of when and where the volcano may erupt and the hurricane may make landfall.

that the Soufriere Hills volcano on the Caribbean island of Montserrat is starting to erupt just as a hurricane approaches. A web-delivered program created by the Wheeling team, provides videos, images, maps and a continuing stream of changing eruption and hurricane data that students plot and analyze to predict upcoming events and make decisions for transporting islanders to safety. Middle school students on four teams - volcano, hurricane, evacuation and communication - apply their science knowledge and math skills to determine if, when and where the volcano will erupt, and if, when and where the hurricane will make landfall. As these calamities evolve, the evacuation team determines the best routes and transportation needs to evacuate residents to safe areas, while the communication team coordinates science information and predictions with the rescue operation. There is uncertainty if the teams will save the residents, and palpable feelings of success if/when they do. Students are so immersed in the simulated mission that they often ask at the end if everyone is safe (Figure 4).

$O M$ and subsequent simulations are complete curriculum packages. Prior to conducting a sim, teachers receive instruction about the science and math issues, the simulation software, and technical requirements. Additional modules describe problem-based learning, which is the theory that guides sim development. During the one to two weeks before the day of the sim the teacher uses provided cross-curriculum lesson plans to review relevant science. Students are assigned roles, and learn the computer interface they will interact with during the mission, preparing them with skills and experience needed to perform their jobs on mission day. The curriculum is based on national standards regarding science, math, problem-solving, and critical thinking skills, as well as life skills promoting teamwork and communication.

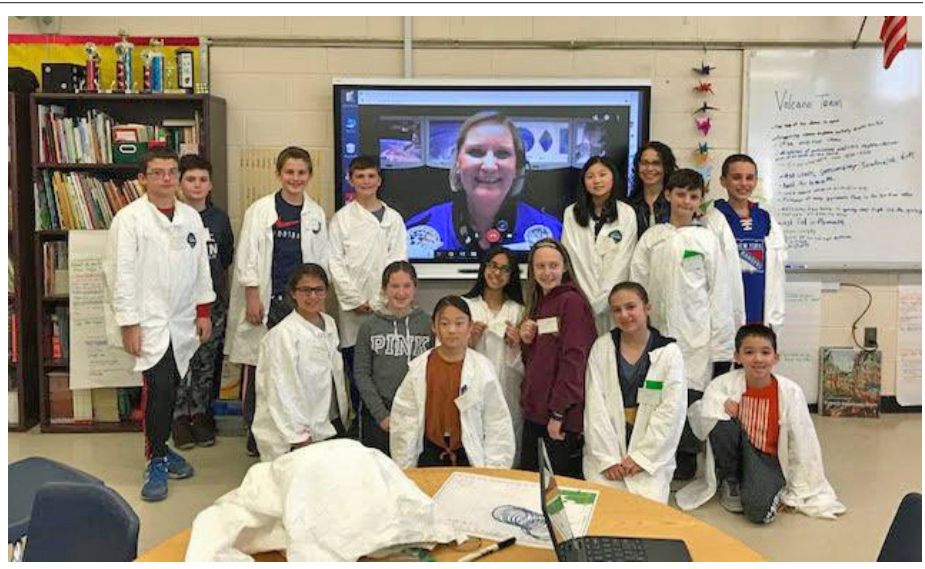

Figure 4. A class of students and their flight director who have just successfully completed (and rescued the endangered population) an Operation Montserrat e-Mission.

After a mission, teachers commonly devote one or two class periods reinforcing sim learning and experience. Significant additional curricular, career and related materials are provided for use independently of the simulation or as supplements to it. A mission experience for an entire classroom requires four or five teams, accommodating up to 36 students, all guided by a single flight director. The simulation experience for the classroom costs $\$ 400$ to $\$ 550$, depending on the sim and the number of sims a school purchases. According to Nancy Sturm (personal communication), the WCLC's first director, the price was set to cover direct and indirect costs plus the cost of equipping the booths from which sims are delivered. The supplemental materials are always freely available for anyone to use.

e-Labs - a Second Solution. The success of e-Mission simulations led to the realization that few missions reached elementary school students or covered more introductory STEM topics. A needs survey of 50 teachers across West Virginia determined that elementary and middle schools need lessons and lab demonstrations of STEM concepts that often were not available in their classrooms. Frequently the teachers reported not feeling confident about teaching and demonstrating the material, the schools had limited laboratory access or none at all, no certified science teachers, and strict safety rules (such as not allowing paperclips which could be a danger if poked in eyes) that prohibited lab-like activities. E-Labs (http://www.e-missions.net/elabs/), and later $e$-Labs $J r$ (http://www.clce-labsjr.net/), were created to fill this void. These live interactive presentations are Skyped from our college-level science lab (Figure 5), with the flight director dressed in a lab coat and wearing goggles to promote safety awareness.

Topics explored by e-Labs (Table 1b) were based on reported teacher needs, and national standards and requirements for appropriate grade levels. Kitchen Chemistry and Seasons offer explorations and explanations to young stu- 


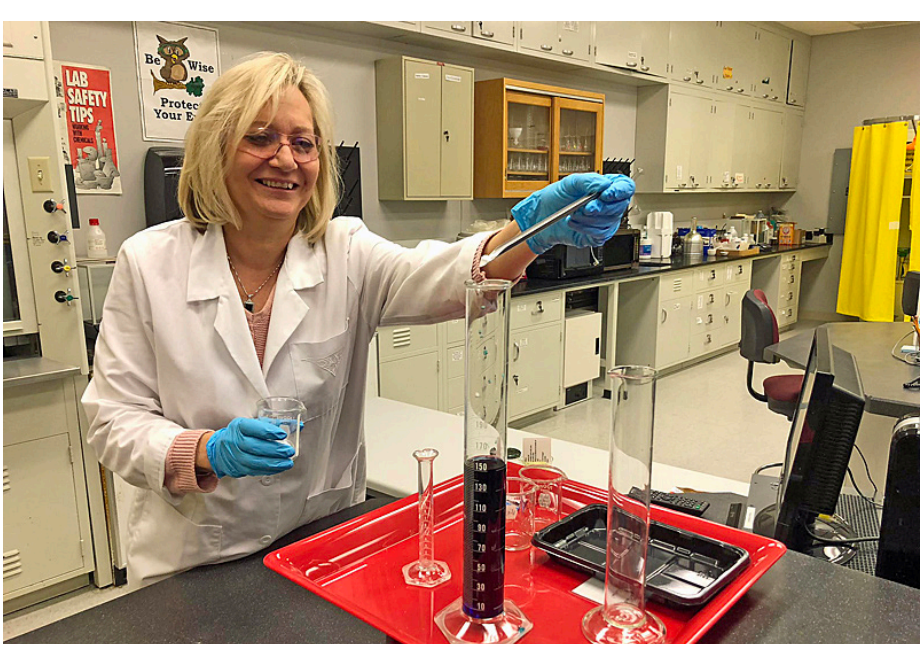

Figure 5. A flight director conducts a live $e L a b$ science experiment with a video-conference connected classroom of students predicting what will happen.

dents for phenomena they know from their own lives. e-Labs such as Matter Matters, Electricity, Chemical Reactions, and The Electromagnetic Spectrum provide introductions to understanding of scientific forces that are invisible but affect things students observe.

The $e$-Labs, and e-Labs $J r$ experiences were developed as 60-minute live demonstrations with flight directors performing experiments while continually asking students - via two-way Skype communication - what could be done to investigate a topic, what the result of an experiment might be, and why it happened. Both $e-L a b s$ and $e-L a b s J r$ are interactive classroom activities, with student questioning and journaling, by writing or drawing, what the flight director does and what the students expect to happen. It turns out that a small foamy explosion of elephant toothpaste, with hydrogen peroxide chemically reacting with dish detergent, is just as unexpected and exciting through a live Skype connection

Table 1a. e-Missions. Funding periods are approximate.

\begin{tabular}{llll}
\hline SIM & $\begin{array}{l}\text { Funding } \\
\text { Period }\end{array}$ & $\begin{array}{l}\text { Grade } \\
\text { Range }\end{array}$ & Funder \\
\hline Operation Montserrat & $1997-1999$ & $5-9$ & NASA \\
Storm-e (Dayton and NY) & $2002-2005$ & $4-6$ & NASA \\
Satellite Rescue & $2002-2005$ & $5-8$ & NASA \\
Target Moon & $2002-2005$ & $6-8$ & NASA \\
Fire Scene Investigation & $2002-2005$ & $6-8$ & NASA \\
Moon Mars \& Beyond & $2003-2004$ & $3-5$ & Computer \\
& & & Associates \\
Space Station Alpha & $2006-2007$ & $5-8,9-12$ & Verizon \\
Cyber Surgeons & $2006-2012$ & $9-12$ & NIH \\
Hurricane Alert & $2007-2008$ & $5-9$ & NOAA \\
West Virginia Storm & $2007-2008$ & $5-9$ & NOAA \\
Pandem-Sim & $2014-2019$ & $11-12$ & NIH \\
Natural Disasters \& Health & $2019-2024$ & $6-8$ & NIH \\
& & (in prep.) & \\
\hline
\end{tabular}

Table 1b. e-Labs. Funding periods are approximate.

\begin{tabular}{llll}
\hline SIM & Funding Period & $\begin{array}{l}\text { Grade } \\
\text { Range }\end{array}$ & Funder \\
\hline Science Magic & $2012-2014$ & $3-5$ & Benedum \\
Kitchen Chemistry & $2012-2014$ & $4-6$ & Benedum \\
Matter Matters & $2012-2014$ & $4-7$ & Benedum \\
Seasons & $2012-2014$ & $4-7$ & Benedum \\
Newton's Law 1 & $2012-2014$ & $4-8$ & Benedum \\
Newton's Law 2 & $2012-2014$ & $4-8$ & Benedum \\
Newton's Law 3 & $2012-2014$ & $4-8$ & Benedum \\
Electricity & $2012-2014$ & $5-8$ & Benedum \\
DNA & $2012-2014$ & $6-8$ & Benedum \\
Volcano! & $2012-2014$ & $6-8$ & Benedum \\
Chemical Reactions & $2012-2014$ & $6-9$ & Benedum \\
Electromagnetic Spectrum & $2012-2014$ & $6-9$ & Benedum \\
\hline
\end{tabular}

as in a classroom.

Through competitive grants, the Pittsburgh-based Benedum Foundation funded the design, construction and testing of all $18 e$-Labs and e-Labs Jr. Although no formal evaluation was required, pre-post-surveys found that teachers and students like the labs. Teachers appreciate the live demonstrations occurring in their classrooms with no requirement for them to set up, conduct and then clean up experiments. Here are some of the teacher responses to the e-Labs:

- "I cannot say enough about this lab! It truly was amazing! The students loved it. Meeting the beekeeper was an extra thrill! I myself was so impressed. This was a great unit and a terrific lab!"

- "This is a wonderfully motivating way to present a science lesson! Hopefully there will be money in the budget to continue this worthwhile program!"

- "Love the experiments that I can do with my students. I also like that there are a variety of experiments surrounding one concept."

- "I loved that it was interactive."

- "This is a valuable tool which will benefit student participants. The features will lead to increased knowledge that would not occur without this experience."

Table 1c. e-Labs Jr. Funding periods are approximate.

\begin{tabular}{llll}
\hline SIM & $\begin{array}{l}\text { Funding } \\
\text { Period }\end{array}$ & $\begin{array}{l}\text { Grade } \\
\text { Range }\end{array}$ & Funder \\
\hline Kitchen Science & $2015-2016$ & K-3 & Benedum \\
Sense-sational Science & $2015-2016$ & K-3 & Benedum \\
Want to be an Astronaut? & $2015-2016$ & K-3 & Benedum \\
Let's Dig Up Dinner & $2015-2016$ & K-3 & Benedum \\
We Have Art Down to a Science! & $2015-2016$ & K-3 & Benedum \\
"BEE" Amazed & $2015-2016$ & K-3 & Benedum \\
\hline
\end{tabular}


A Developing Suite of e-Missions and e-Labs. Since the creation of Operation Montserrat, 11 subsequent $e$-Missions and $18 e-L a b s$ and $e$-Labs $J r$ (Tables 1a-1c) have been developed with funding from NASA, NOAA, NIH, the Benedum Foundation and corporations. The WCLC and Center for Educational Technologies, both at Wheeling University, have jointly developed 11 e-Missions, but WCLC alone created all the $e$-Labs. Three major simulation initiatives resulted from National Institutes of Health (NIH) funding through their Science Education Partnership Awards program (SEPA). In 2006, a SEPA grant was received to create CyberSurgeons (http://www.e-missions.net/cybersurgeons/), a live simulation in which high school students perform as doctors on a virtual ship sailing up the Amazon. At ports of call, students diagnose and recommend treatment and clinical trials for Brazilians who come to the ship, and for onboard researchers who develop ailments.

A second SEPA grant in 2014 allowed the development of PandemSim (http://www.pandemsim.com/), during which 10th to 12th graders serve as epidemiologists examining patient symptoms, disease progression and transmission to identify the pathogen causing an outbreak and to recommend treatment and ways to contain the epidemic or pandemic (Wood et al., 2018). In 2019, the Wheeling team received another SEPA grant to create Natural Disasters \& Health, a middle school simulation of the health consequences of natural disasters such as earthquakes, tornadoes, volcanic eruptions, and hurricanes (https://www.disasterhealth.net/).

Statistics. The WCLC sim missions have been developed, one by one, with different funding sources (Tables 1a-1c). Development and evaluation cost for a single e-Mission ranges from about $\$ 200,000$ to more than $\$ 1,000,000$ depending on the complexity of each mission; e-Labs development costs are roughly ten percent of e-Mission costs because they are much less complicated, requiring almost no coding nor complex interfaces.

Missions are developed separately with major goals typically being improvements in using and understanding relevant math and science topics, along with learning to collaborate and share analyses and information throughout a mission. By playing the roles of scientists and engineers, students experience working as such specialists do, and supporting material provides additional career information.

The number of students participating in each mission depends on class sizes of various grade levels. K-5 missions typically have 20-24 students, and middle school to high school missions involve 28-36 students.

Because most e-Missions are funded separately, evaluations are generally for just a single mission; only the 12 $e$-Labs (all funded by a single grant) have been evaluated as a group. Student demographics are collected only during formal evaluations, when there is commonly a funding agen- cy requirement to have a diversified array of students. Typically, minority students and female students are priorities for inclusion. During the years of offering missions after development funding ends, diversity statistics are not collected.

During the 2017-8 school year, 584 of the 768 total missions delivered by the WCLC were e-Missions, and 184 were traditional onsite CLC missions. e-Missions bring the thrill of a CLC mission to students who live nowhere near a brick and mortar Challenger facility. Schools or sponsors pay for every e-Mission experience. Because the SEPA and other simulations were developed specifically to be offered as $e$-Missions, nothing of the sim core design or supplemental content has to be modified for sustainability. Because the Wheeling CLC/CET team is quite experienced in the design and operation of the 20-year sequence of virtual missions, development of each $e$-Mission builds on prior accomplishments to create a new engaging experience that combines science, teamwork, changing situations and crises with excitement and fun.

Pecuniary evidence of impact of e-Missions is that in the seven years since the end of CyberSurgeons grant funding, that e-Mission alone has been presented 418 times, reaching 10,900 students in 60 schools, and generating an average revenue of $\$ 27,000$ per year. Considering all e-Missions, between 1998 and 2018, 11,338 e-Missions were presented to schools in 50 states and 22 foreign nations, 309,282 students participated, and about 10,000 teachers were trained. During this period, slightly more than $\$ 5,000,000$ in income was generated. Yearly income from all missions is $\$ 250,000$ to $\$ 300,000$, all supporting the WCLC staff in delivering the sims and updating simulation software and hardware. Examples include rewriting of $O M$ in 2012 to upgrade the original 1998 version, and purchasing four sound-proof booths (Figure 2) to provide compact studios for flight directors to videoconference with students. The most popular $e$-Missions are OM, CyberSurgeons and Space Station Alpha; the most popular e-Labs are Chemical Reactions, Science Magic, Matter Matters; and for the younger group, Bee Amazed and Kitchen Science Fun. Note that income from all sims is combined, supporting sustainability for all 30 virtual offerings, with priority going to the most used sims.

Income from offering missions has to cover all aspects of our simulations, except development, which is paid by grants. Normal operating costs include (1) presenting new sims at national and regional education conferences to recruit new teachers and schools; (2) registering and scheduling each of 700 or so missions (schools often change dates); (3) financial charging and tracking of payments; (4) training flight directors (FDs) - we normally have 12-15 to staff our heavy mission schedule; (5) purchasing needed booths, computers and other equipment; and (6) working with kids during missions. 
Funding, Partnerships and Sustainability. Funds for schools to pay for e-Missions and e-Labs - and hence our sustainability - come from a variety of sources. Individual schools commonly pay for sims, and some school districts do bulk mission purchases (at a discount) for use by schools throughout their districts. Challenger programs are often funded by school organizations such as PTO, science clubs, etc. Similarly, magnet, cyber and alternative schools often raise funds for missions, as do Scouts, 4-H clubs, science clubs, and after-school programs. If funds cannot be raised locally, some teachers seek grant funds to acquire access to our Challenger programs. Examples of larger organizations that have recently funded student access to e-Missions include Beating the Odds, which helps students overcome obstacles associated with their home environments, Remake Learning, a Pittsburgh group that brings understanding of modern technologies to education, and Wheeling's Women's Giving Circle, a local community foundation that has funded six of our Girls in Space camps that include e-Missions and e-Labs.

Our Wheeling CLC has also been funded directly by state educational offices, community foundations (especially the Benedum Foundation), and commercial groups such as American Electric Power Company (AEP), Verizon, the Bayer Corporation, and Chevron, to provide scholarships for $e$-Missions and to develop entirely new sims. Additionally, WCLC partnered with Pittsburgh's Carnegie Science Center to demonstrate how to conduct distance learning, and WCLC trains teachers to write proposals to their local businesses and foundations for their schools to participate in e-Missions.

Extended partnerships (defined as more than a single donation, grant or shared activity) have been developed with a number of entities. NASA was a long-term partner of $e$-Missions, having funded the development of five missions, and having used $e$-Missions in each of the 150 schools in the NASA Explorer Schools program (Ruberg, Chen, \& Martin, 2007). Also, very important, was that for nearly 20 years the WCLC program was a line item in the budget of the WV State Department of Education. This funding allowed updating of hardware and paying salaries, as well as providing missions to schools across the state. A new partner is the WV Department of Education's Office of Diversion and Transition programs, for which WCLC provides the excitement and inspiration of e-Missions to incarcerated kids in every West Virginia juvenile facility. This is especially rewarding both for us and the students, as exemplified by this comment from an evaluation by one participant: "I ain't gonna lie. For the last two hours I forgot I was behind bars."

Here are two more collaborations that support sustainability. CyberSurgeons and Pandem-Sim missions are typically presented every year as part of the Health Science Technology Academy (HSTA) summer programs at Mar- shall University. Additionally, the WV Space Grant Consortium has repeatedly funded development of new activities as well as teacher training using our online $e$-TechTeach flipped learning concept (http://www.e-techteach.com/).

Schools and districts have partnered in pilot testing and evaluation of various of WCLC's sim missions. The nearby Mount deChantal Visitation Academy was a long-time collaborator, with one faculty member repeatedly advising on the development of missions and in pilot testing. That teacher has since joined our CET team at WU. Many other schools have been involved in evaluation of new sims.

\section{RESULTS}

Results can be measured by formal evaluations, numbers of missions sold each year, and awards and recognition. Evaluation by Chen and Howard (2008) of the first sim, Operation Montserrat, identified significant positive changes in student attitudes and perceptions toward scientists. Their evaluation of 311 middle school students and seven teachers in four states concluded that the simulation improved student interest and attitudes toward science. Significantly, male students experienced higher gains than females, consistent with previous studies (e.g., Gardner, 1975). Additionally, teacher preparation and teaching of pre-mission content had a strong impact on student content knowledge and interest, indicating that engaging simulations are more effective when teachers use effective teaching strategies.

A formal evaluation (Calinger and Piecka, 2011) of the CyberSurgeons e-Mission involving 82 teachers and 1,304 students found statistically significant improvements between pre-mission and post-mission scores $(p<0.001)$ for content knowledge, critical thinking/problem solving, communication/collaboration, and ability in dealing with challenges. A similar formal evaluation of Pandem-Sim used a randomized block design with pre- and post- simulation surveys. Evaluation was conducted in 32 high school classrooms in 11 states. Of the 575 students who participated in the evaluation, $16 \%$ identified as minority, $81 \%$ as white. Evaluation highlights include that $99 \%$ of students enjoyed the Pandem simulation to some degree, and only $1 \%$ didn't, indicating that the activity was engaging. Seventy-six percent of students said that the simulation increased their interest in pursuing a career in epidemiology or a biomedical or healthcare field, and $82 \%$ reported that participation increased their confidence that they had the abilities to pursue such careers. This is evidence of success in the goal of increasing interest in relevant careers. There was no significant gender difference in knowledge or career outcomes. An intriguing finding was that students had higher content learning scores and increased career interests if their teachers thought that their students would find epidemiology interesting, and if teachers believed that they were well prepared to 
teach the pre-mission preparation. As in the OM evaluation described above, teachers were critical for learning and developing interest in this simulation, as they are in every other aspect of learning.

The WCLC missions have won much acclaim, with various WV governors and other state officials visiting, and an e-Mission was demonstrated to President G.W. Bush. $O M$ has also received many awards over the last 20 years including inclusion in the NSF-funded Digital Library for Earth System Education (DLESE) "Reviewed Collection," the highest level of recommendation for STEM electronic learning tools. Similarly, listing of WCLC's e-Mission programs by the Center for Interactive Learning and Collaboration (CILC) led to multiple repeat users, and because of their feedback, WCLC was selected as a Pinnacle Award recipient - the highest level of CILC recognition.

\section{DISCUSSION}

The WCLC, with its vibrant traditional onsite program, and especially its innovative $e$-Mission offerings, has been a major success since becoming a Challenger Learning Center. Nearly every year WCLC is ranked as one of the top Centers in terms of the number of students and teachers who participate in Challenger missions. The model we have developed has worked for teachers, students, and the sustainability of WCLC, however, it has not been as successful for eight other CLCs, which licensed e-Missions in 2008. Exact reasons are not known but e-Missions are complex and require significant training of flight directors for missions to work effectively. Perhaps more importantly, the concept of $e$-Missions was created by the Wheeling team and there is a strong sense of ownership and pride in them. Additionally, the WCLC's director (Jackie Shia) has worked at the Center for 24 years, the assistant director (Lori Kudlak) for 17 years, and flight directors often stay with the program for five to ten years - there is long-term buy-in. Finally, the WCLC leadership team is relentless and creative at marketing missions and developing new sponsors and grants, doing whatever it takes to succeed, including delivering missions to classrooms on the other side of the planet in India, South Africa or Korea at 2 to 4 A.M Wheeling time.

Considering the long-term sustainability of the Wheeling CLC/CET team in developing and marketing engaging STEM experiences, are there lessons that other STEM projects can adopt to expand their market and their sustainability? The answer is yes, but each project must modify the approach to fit and enhance their specific activity.

- First, a project must be perceived as being truly unique, unlike anything available locally, at a minimum.

- Second, it has to be a large enough product that matches curricular needs to warrant a substantial pay- ment; for example, a package including a mission experience (or a live lab), lesson plans, and substantial pre-mission support for teachers and students.

- Third, there must be upfront funds to transform the product from classroom delivery to a dynamic, live online experience (not just a webpage). Ideally, funding to accomplish this should be written into initial grant proposals used to create the project. This means that the initial project must be designed to be ready to operate beyond a single classroom.

- Fourth, in order to earn adequate funds to truly sustain and enhance the initial project (which presumably is excellent if it were selected in rigorous peer-review), it must be marketed to a vastly larger audience beyond already known local schools.

- Finally, even a sensational project fails if it is not successfully marketed. We inform teachers of the existence of a new simulation by presenting it at regional and national science education conferences, writing articles in science education journals, and emailing teachers who have been customers for previous sims. The WCLC commonly starts marketing a new e-Mission to teachers who had participated in the project's pilot studies or the main evaluations. They already have experienced the project, probably helped to improve it, and hopefully feel some ownership. Such teachers are often ready to find school funds to bring the mission to their classes, sometimes for years to come.

Transforming a class or lab-based project to an e-Mission type simulation takes much more effort and skill than converting an existing demonstration or small lab exercise to a live videoconference such as an $e-L a b$. There are markets for both - especially considering that nearly all the world's schools are now accessible through videoconferencing. While funding largely comes from American sources that want projects for use in the United States, once a virtual version is created it can also be marketed abroad to secure extra funds to allow STEM educators to create more innovative programs for American and other students.

\section{AUTHOR NOTE}

It is ironic that this paper describing our sustainability for nearly 25 years is revised when our WCLC can no longer sustain itself. The Covid-19 virus has closed every K-12 school in America and most of the world, so that none of our clients are available. Additionally, our university has laid off our CLC staff and other employees until recovery sets in. We have learned that our very successful Challenger model only works when the world's education system works. Our hope is that when schools reopen, teachers will remember- 
and have funds - to resume using e-Missions to inspire and educate their students.

\section{AUTHOR INFORMATION Corresponding Author}

Charles A. Wood, Center for Educational Technologies, Wheeling University, Wheeling, WV 26003. (301) 5385244.chuckwood@wju.edu

\section{Author Contributions}

The manuscript was largely written by Charles Wood with contributions, review and approval by coauthors.

\section{ACKNOWLEDGMENTS}

The authors have been involved in creating, pilot testing, and evaluation of most of these sims, and we thank many other contributors, especially Manetta Calinger and Debbie Tyrrell. Routine daily delivery during the last two decades was accomplished by dozens of educators working at our Challenger Learning Center as Flight Directors, so named because early funding was from NASA and simulations were mostly of space missions.

\section{FUNDING SOURCES}

This paper reports work conducted over more than 20 years. Funding for simulation development has come from many sources including NASA, NOAA, NIH, Verizon, Computer Associates, Benedum Foundation and others. Research to prepare this publication was supported by the Science Education Partnership Program Award from the National Institute of General Medical Sciences of the National Institutes of Health under award number R25GM132909. The content is solely the responsibility of the authors and does not necessarily represent official views of the National Institutes of Health.

\section{ABBREVIATIONS}

AEP: American Electric Power Company; CILC: Center for Interactive Learning and Collaboration; CLC: Challenger Learning Center; DLESE: Digital Library for Earth System Education; FD: Flight Director; HSTA: Health Science Technology Academy; NIH: National Institutes of Health; OM: Operation Montserrat; SEPA: Science Education Partnership Award; WCLC: Wheeling Challenger Learning Center

\section{REFERENCES}

Calinger, M., and Piecka, D.C.B. (2011). Integrating a live medical simulation into a high school anatomy and physiology curriculum: Cybersurgeons. In Proceedings of Society for Information Technology and Teacher Education International Conference 2011 (pp. 2067-2074). Chesapeake, VA: AACE.

Chen, C-H., and Howard, B. (2008). Effect of live simulations on middle school students' attitudes and learning. Educational Technology and Society, 13(1), 133-139.

Gardner, P.L. (1975). Attitudes to science. Studies in Science Education, 2, 1-41.

Piecka, D. C. B., Calinger, M., Wood, C., Shia, J., Kudlak, L., and Tabachnick, B. G. (2012, April). Evaluation of a live high school clinical science education simulation. Paper presented at the annual meeting of the American Educational Research Association, Vancouver, BC, Canada.

Ruberg, L., Chen, C-H., and Martin, J. (2007). NASA Explorer Schools project evaluation: Summer 2003 to spring 2006. Center for Educational Technologies, Wheeling Jesuit University, final report submitted to NASA.

Wood, C.A., Tyrrell, D., Calinger, M., Shia, J., Kudlak, L., and Ondeck, L. (2018). Pandem-Sim: Development and pilot testing of a live simulation of infectious disease outbreaks. Journal of STEM Outreach, 1(1), 1-7. 